\title{
Resistivity Based Low Cost Mastitis Level Detection System
}

\author{
Harpal Singh, Kanika Chhabra, Rinkesh Mittal
}

\begin{abstract}
Mastitis is universally considered the most wide spread and costly disease of the dairy industry. It can be defined as an inflammation of mammary glands in the udder tissue. Mastitis is a disease complex due to different causes, various degrees of intensity, variation in disease duration and residual effect. India has ranked as the highest milk producing country among the world. In a survey conducted by FAO for top milk producing countries, it is estimated that by the year 2021 India will be ranked as the number one country for milk production. In small areas of Punjab and Haryana where the farmers are illiterate and are not aware about the proper health conditions of cattle, then there are ultimate chances of cattle to have mastitis. In this work we present low cost solution for detection of mastitis level on the basis of resistivity of milk. The survey conducted in three different regions of Punjab (Bathlana, Mansa, Badmajara) where cattle with mastitis and their milk was tested, tests were also presented. It was found that milk production rate has been declined by the unawareness of the dairy holders, as they don't know much about the causes of mastitis. The presented method provides comparable results for the detection of mastitis level at low cost based on ionic concentration of milk.
\end{abstract}

Index Terms: Mastitis, Resistivity, milk samples (key words)

\section{INTRODUCTION}

Milk is a wholesome food, it provides all the necessary nutrients, vitamins, and proteins that are required for human consumption. It is very important for the consumers that the milk that is to be consumed is healthy and pure. From last few decades, there is a devastating reduction in the quality of milk because of mastitis. Mastitis has become a threat worldwide that has reduced the quality and quantity both of milk production. Mastitis is a disease that declines milk production and cause a great impact on the cattle

Health, with these consequences of mastitis, not only consumers but cattle also suffers. It is an inflammation of mammary glands in the udder tissue that is caused by the pathogens present in the surroundings of the cattle. Because of mastitis the milk produced by the cattle with mastitis is not healthy, and the milk is not suitable for

Human consumption. Milk's natural composition changes with different factors such as age of the milk, lactation stage, season, breed of cattle [7]. When any bacteria harms the udder of cattle, it alters the chemical properties of milk. The milk

Revised Manuscript Received on July 09, 2019.

Dr. Harpal Singh, Department of Electronics and Communication Engineering, Chandigarh Engineering College, Landran, Mohali, India

Kanika Chhabra, Department of Electronics and Communication Engineering, Chandigarh Engineering College, Landran, Mohali, India

Dr. Rinkesh Mittal, Department of Electronics and Communication Engineering, Chandigarh Engineering College, Landran, Mohali, India ionic concentration changes, this ionic concentration is measured in terms of electrical resistivity of milk. It is a measure of ability of milk to resist electrical current [5]. Ionic concentration of milk is directly related to amount of salts in milk. Milk with higher concentration of salts such as $\left(\mathrm{Na}^{+}, \mathrm{cl}^{-}\right)$ will have low resistivity, and milk with lower concentration of salts $\left(\mathrm{K}^{+}\right)$will have high resistivity and vice-versa. The concentration of salts in the milk are affected by variations in the temperature of milk. Survey was conducted in three different regions of Punjab (Bathlana, Mansa, Badmajara) as Punjab is one of the highest milk producing states in India. But mastitis has resulted in economic losses such as $70 \%$ reduction in the milk yield, $9 \%$ of milk is discarded after treatment, $7 \%$ veterinary charges, and $14 \%$ losses due to the premature culling.

\section{RELATED WORK}

Marcus Henningsson, [1], (2007), the electrical conductivity of milk at various dilutions was measured at different temperatures from 2 to 70_C. Increasing temperature has a positive effect on conductivity of milk. The results showed that dilution has only a small influence on the temperature dependence of conductivity. Milk's composition changes naturally with age of milk, lactation, season, breed of the cow. A simple power-law model predicts that the conductivity is proportional to the milk concentration to the power of 0.84 and a two-term model describes the temperature dependency.

Chen Ming-Chih, [2], (2014), developed the design of information system for detecting mastitis level in dairy cattle and managing their milk processes. The system protects humans from consuming the contaminated milk as it prevents from milking infected cows (mastitis suffered cows). The proposed system can easily search out the infected cows at early stage and with the help of the database the data can be stored in it about the health status of each cow by their respective RFID readers and the farmer will be updated about the health status of cattle. This improves the efficiency of milk production.

Francesca Gabriele, [3], (2014), focused on the occurrence of mastitis in the developing countries and the risk factors that are caused by mastitis. Temperature is an important factor for mastitis, cattle with high temperature habitat can easily have mastitis. It was estimated that cows are more prone to the disease than buffaloes in small scale dairy production systems. It also provides

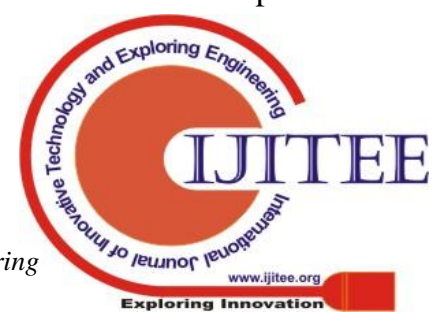


information on the economic dimensions of the disease in resource poor-environment. Concluded that mastitis is an endemic disease and requires broad-based effort to control and decrease its occurrence.

Shagufta Fahmid, [4], (2016), proposed that electrical conductivity is the best method for determination of mastitis in cattle. Milk's electrical conductivity (Electrical Conductivity) is usually determined by its ionic concentration, due to mastitis the concentration of sodium $\left(\mathrm{Na}^{+}\right)$and chloride $\left(\mathrm{Cl}^{-}\right)$ions increases and there is a decrease in concentration of potassium $\left(\mathrm{K}^{+}\right)$and lactose in milk. Concluded Electrical Conductivity (EC) as the most reliable technique for mastitis and shows EC results for healthy milk samples ( $5.48 \mathrm{mS} / \mathrm{cm})$, sub-clinical mastitis milk samples( $6.3 \mathrm{mS} / \mathrm{cm})$, clinical mastitis milk samples $(8.5 \mathrm{mS} / \mathrm{cm})$.

Mandheer Kaur, [5], (2016), focused on the variations in the sub-clinical and clinical mastitis in cows and buffaloes. Presented the results of various tests performed on number of cattle of Bathlana, Mansa, Badmajra.

Jurjen Draaiyer, [6], (2009), as milk is a wholesome food for the consumers so it should be checked and tested at each stage. It provides information on simple and cost-effective sampling, testing in developing countries. The main objective of the study was to increase milk production thereby increase the income of the milk producers or small-scale entrepreneurs. It also focusses on improving safety and hygienic quality of milk, and no adulterations in the milk. Ensures that the milk producers get the fair payments.

I.Panchal, [7], (2015), presented a new parameter for detecting mastitis (sub-clinical), a relation between electrical conductivity, and dielectric constant and somatic cell counts results as a detector for sub-clinical mastitis. For this many different tests were performed such as $\mathrm{pH}$ test, electrical conductivity, and somatic cell counts separately.

Daniella Flauia Vilas Boas, [8], (2017), focused on the quality of the milk by the different mastitis test on the basis of electrical conductivity and somatic cell count. Provides a correlation between EC (Electrical Conductivity) and SCS (Somatic Cell Score). Evaluated the udder health on the basis of pooled samples of milk. Concluded that electrical conductivity is a simple, rapid and inexpensive method for measurement of mastitis.

Ferrero Francisco J., [9], (2000), presented a low cost sensor system for the determination of the number of somatic cell count in the milk. Mastitis is the most dangerous disease in the cattle industry from the last few decades and it also leads to financial losses in the milk production. Photomultiplier tube (PMT) is used for the analysis of the number of somatic cell count in the milk of the cow. PMT is a versatile device that provides extremely high sensitivity and ultra-fast response for the detection of mastitis. The result of bioluminescent mastitis were as (+) when ATP content is more than $10^{*} 10^{-10}$ moles $/ \mathrm{ml},(-)$ when ATP content is below $4 * 10^{-} 10$ moles $/ \mathrm{ml}$.

\section{METHODOLOGY}

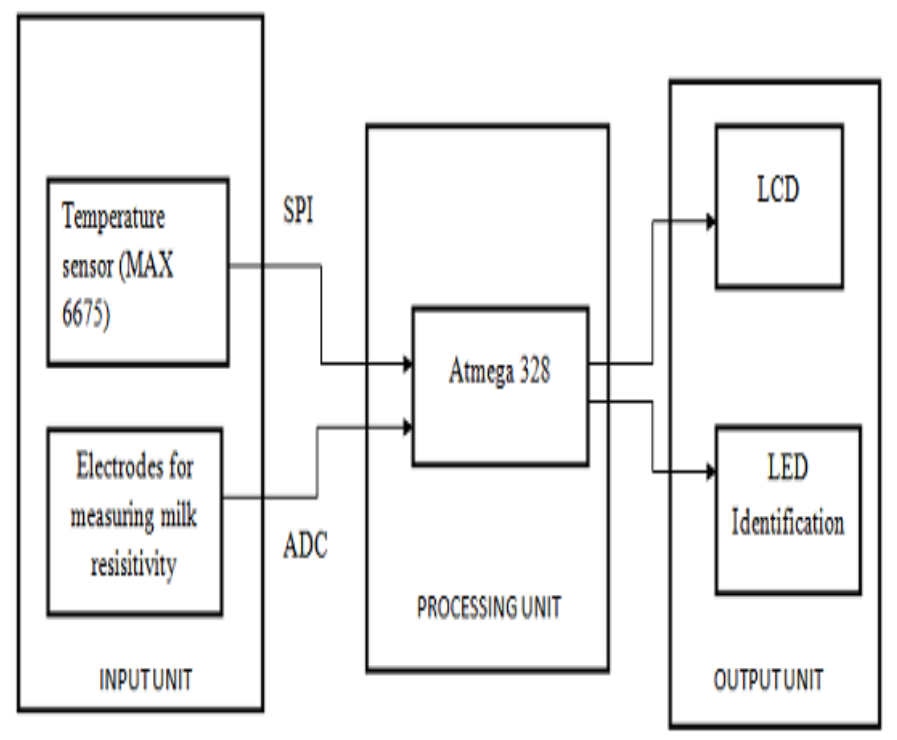

Figure 1: Proposed Setup

In the proposed work represented in Figure 1 has three units named as input unit, processing unit, output unit. The temperature sensor (MAX6675) and resistivity measuring electrodes are in input units. As we provide the system a constant supply of $5 \mathrm{~V}$ and it gets started, milk is poured in the container in which the resistivity measuring electrodes are attached. The electrodes on both sides of the container are of same material, and of same size. Electrodes can be of any metal as per their availability in the market, such as iron, aluminum, silver, gold. Gold, silver and aluminum are very expensive for a small-scale dairy farms. Earlier tests were conducted with iron also, but iron gets oxidized that is why iron was not used.

Electrodes used for this setup are steel electrodes which are easily available at low cost in comparison to gold as well as silver and can be formed in the required shape easily. One side of electrode is attached with VCC, and the other is attached with A0 pins of the micro-controller (Aurdino UNO). These electrodes measure the resistance between the electrodes, and with the help of resistance the resistivity of the milk can be found.

$$
\begin{aligned}
& R=\text { Resistance } \\
& 1=\text { length of the container } \\
& A=\text { area of container } \\
& \rho=\text { resistivity }
\end{aligned}
$$

With the help of resistance we can find the resistivity.

$$
\mathrm{R}=\rho \mathrm{l} / \mathrm{A}
$$

The value of resistance is measured in $\Omega \mathrm{m}$.

In the second unit i.e, processing unit, (Aurdino UNO) microcontroller is used, in which the data is being processed for the determination of milk with mastitis in small scale dairy farms. When the value of resistance is obtained then

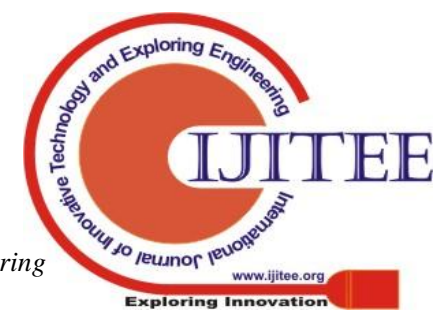


the processor fetches the value of resistance with the provided algorithm that has to be followed. Provided length, width, and height of the container containing milk we can easily calculate the area of the container. As resistivity is directly proportional to area, therefore with the help of resistance we can have resistivity.

Given,

$$
\begin{aligned}
& \mathrm{w}=.0049 \mathrm{~m}, \\
& \mathrm{~h}=.0026 \mathrm{~m}, \\
& \mathrm{l}=.0075 \mathrm{~m},
\end{aligned}
$$

Therefore, Area $(\mathrm{A})=\mathrm{h} * \mathrm{~W}$

$$
\begin{aligned}
& (A)=.0026 * .0049 \mathrm{~m}^{2} \\
& (A)=.0000124 \mathrm{~m}^{2}
\end{aligned}
$$

As we got the value of area we can have resistivity also by:

$$
\mathrm{R}=\rho \mathrm{l} / \mathrm{A}
$$

In the output unit, output of the setup is displayed in two form one by the lcd in analog form and other through different LED light indicating three different ranges of resistivity with three different colors. The green LED light will glow for an acceptable range of resistivity values, the yellow LED will indicate that there is chances to have mastitis (moderate case), and the last LED light i.e, red will show that the resistivity values determined are completely rejected.

Green LED = acceptable range

Yellow LED $=$ moderate range

Red LED = rejected range

The setup produced mainly considers the low cost mastitis detection in small -scale dairy farms. The system used in the large dairy farms and industries are very costly, not in the reach of small-scale dairy farms. The cost of proposed system is approximately Rs.3000/-. The approximate cost of all the devices used in industries and large-scale dairy farms are shown in Table 1.

Table 1. Cost Comparison with Different Techniques

\begin{tabular}{|l|l|}
\hline Name of Technique & \multicolumn{1}{|c|}{ Approximate Cost } \\
\hline pH meters & Rs 7000/- \\
\hline $\begin{array}{l}\text { Online methods (used in } \\
\text { laboratories) }\end{array}$ & Rs 125000/- \\
\hline Setup proposed & Rs 3000/- \\
\hline
\end{tabular}

\section{RESULTS AND DISCUSSION}

In the proposed system, resistivity is used for determination of mastitis level of cattle milk. For determination of cattle milk with mastitis, different milk sample were tested at different temperature ranges from (30C-60C). Normal milk just after milking and milk with little dilution were tested. It is observed that milk concentration does not vary much with dilution in the milk. Milk's concentration varies with the change in the temperature. Resistivity is negative temperature co-efficient, i.e., with an increase in temperature the value of resistivity decreases. By this we get different ranges of resistivity, and these ranges are further classified in three different ranges of resistivity that are shown in Table 2.

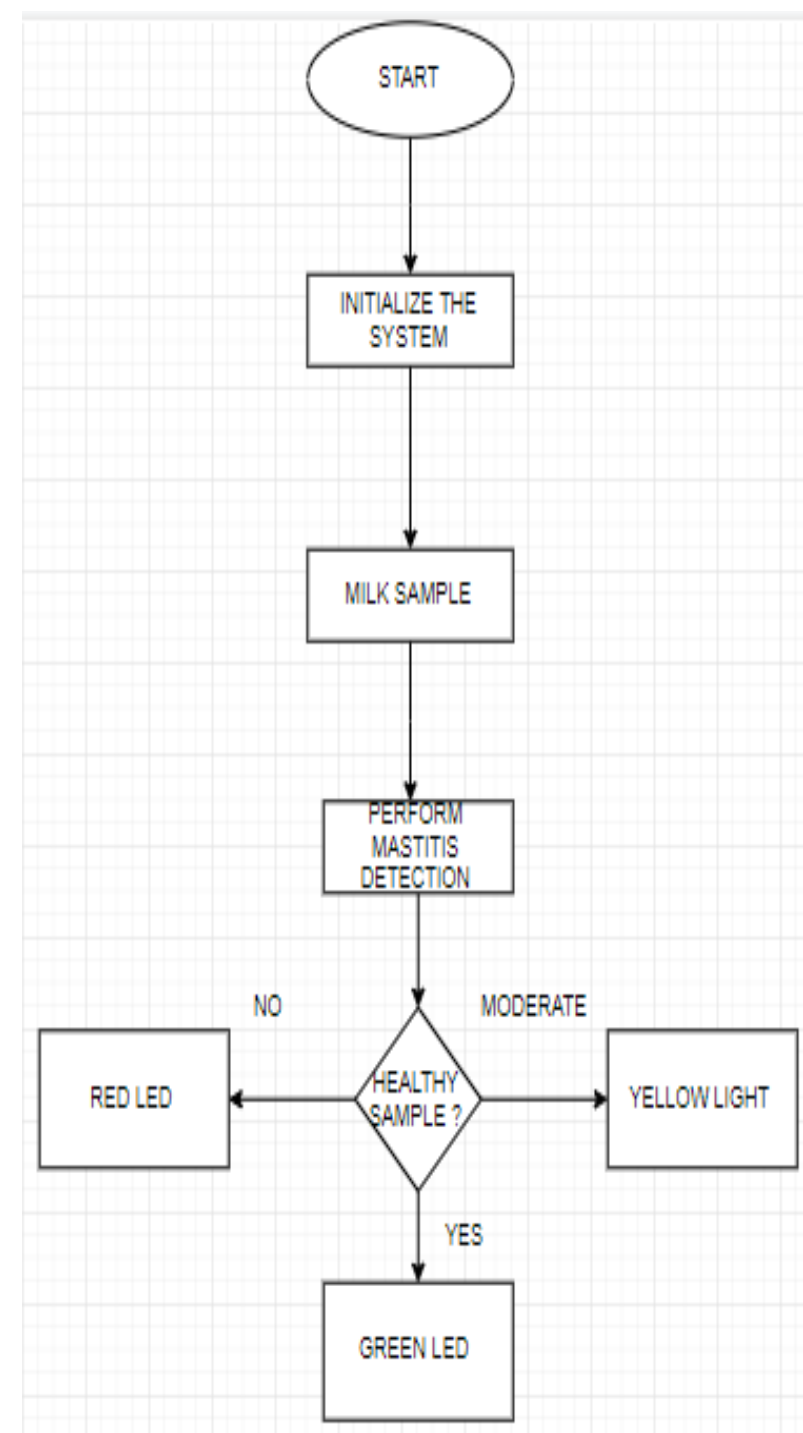

Figure 2: Flow Chart

Table 2. Resistivity Ranges

\begin{tabular}{|l|l|l|}
\hline S.NO & $\begin{array}{l}\text { RESITIVITY } \\
\text { VALUES }\end{array}$ & RANGE \\
\hline 1 & More than $2.00 \Omega \mathrm{m}$ & $\begin{array}{l}\text { Acceptable range } \\
\text { (Green LED) }\end{array}$ \\
\hline 2 & $2.00-1.7 \Omega \mathrm{m}$ & $\begin{array}{l}\text { Moderate range } \\
\text { (Yellow LED) }\end{array}$ \\
\hline 3 & Less than $1.7 \Omega \mathrm{m}$ & $\begin{array}{l}\text { Rejected range } \\
\text { (Red LED) }\end{array}$ \\
\hline
\end{tabular}




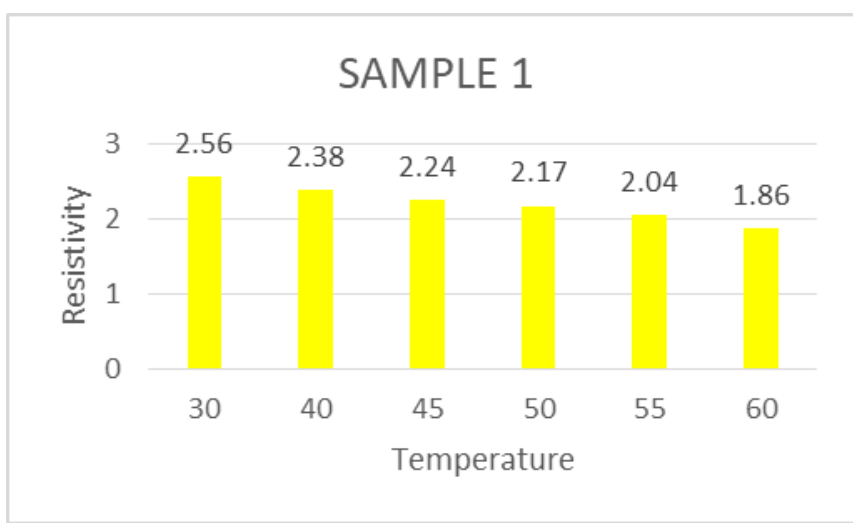

Figure 3: Resistivity v/s Temperature Range Sample 1

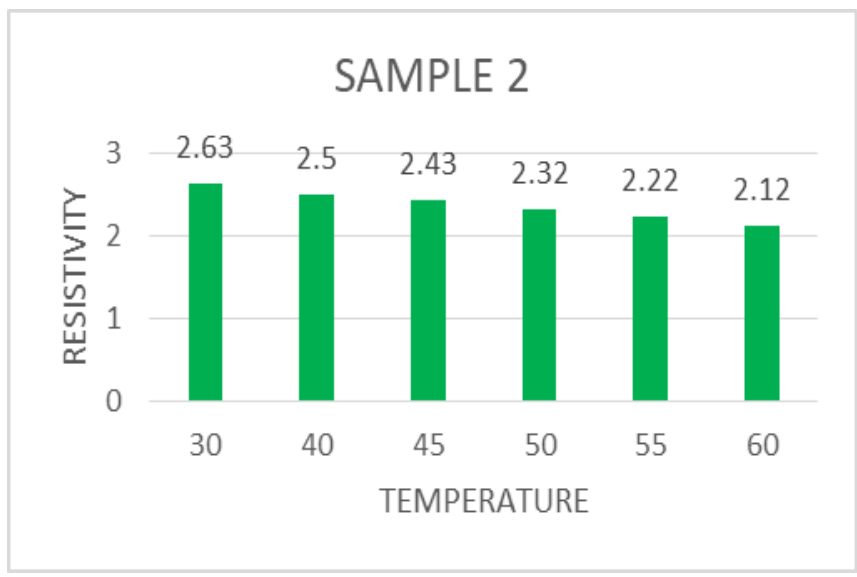

Figure 4: Resistivity v/s Temperature Range Sample 2

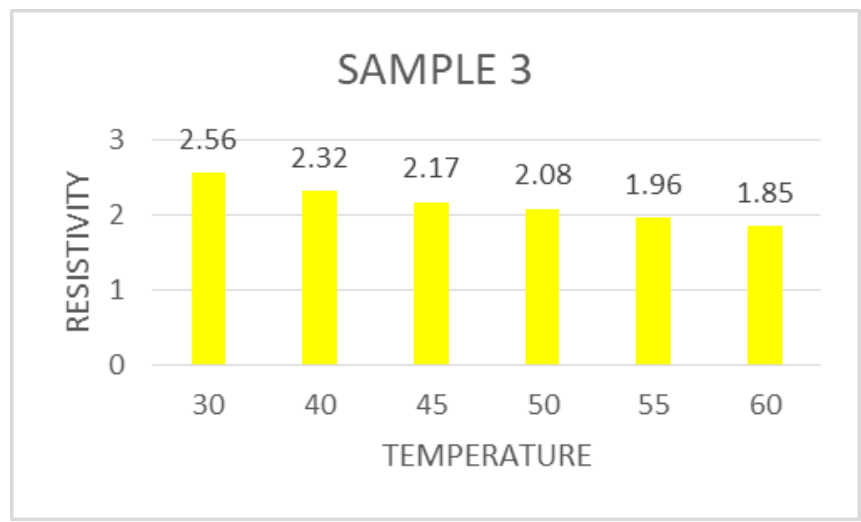

Figure 5: Resistivity v/s Temperature Range Sample 3

Figures 3, 4,5,6,7 shows graphs between resistivity and temperature in which different milk samples were taken to determine the level of mastitis in each sample of cattle milk. The trend of resistivity decreases as with an increase in temperature.

Figure 3 represents a graph between resistivity and temperature, as resistivity is a negative temperature coefficient (i.e. with an increase in temperature the value of resistivity will decrease), the resistivity values falls with an increased temperature but in an acceptable range for this sample as shown in Table 2. Figure 4 here shows the graph of resistivity and temperature but in this case the values of resistivity does not lie in the acceptable range, the milk sample falls in the category of moderate range for detection of mastitis milk. Similarly figure 5, 6 represents graphs with an acceptable and moderate range respectively for the milk samples. Figure 7 represents a graph between resistivity and temperature of a sample that falls in the rejected range for the detection of mastitis in cattle milk.

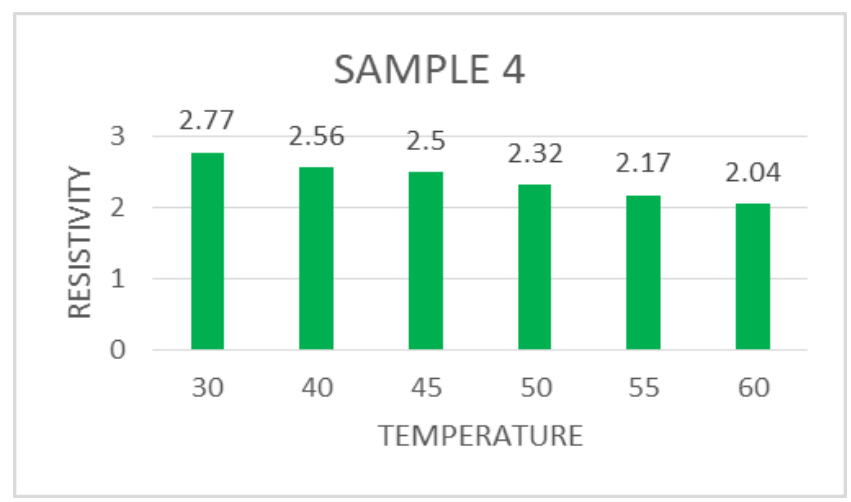

Figure 6: Resistivity v/s Temperature Range Sample 4

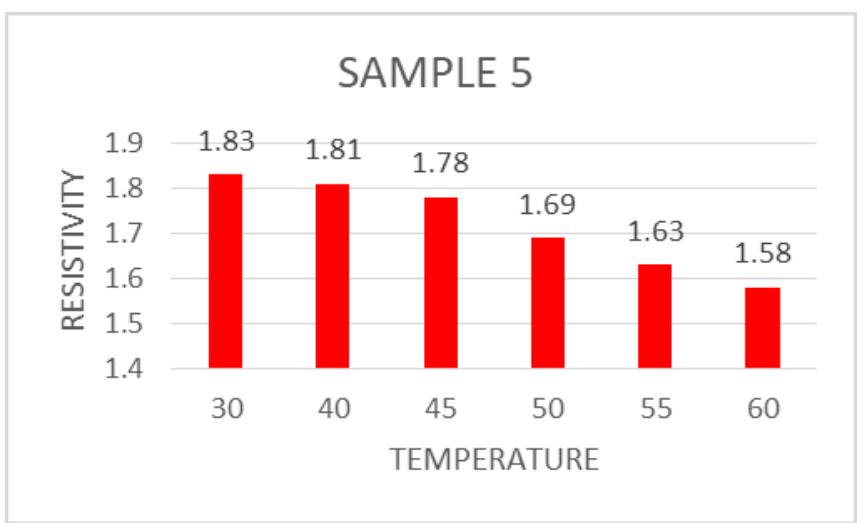

Figure 7: Resistivity v/s Temperature Range Sample 5

Table 3: Milk Samples v/s Resistivity at normal room temperature

\begin{tabular}{|l|l|}
\hline Milk samples & Resistivity (in $\mathbf{\Omega m}$ ) \\
\hline MS1 & 2.63 \\
\hline MS2 & 1.86 \\
\hline MS3 & 2.17 \\
\hline MS4 & 1.63 \\
\hline
\end{tabular}

Table 3 depicts different milk samples and their corresponding resistivity values:

MS1 (milk sample 1) has $2.63 \Omega \mathrm{m}$ resistivity and this is an acceptable range of resistivity for mastitis determination in cow milk. As it is an acceptable range the setup produced will represent the acceptable range of resistivity with a green LED light.

MS2 (milk sample 2) has $1.86 \Omega \mathrm{m}$ resistivity and this range is not acceptable as healthy milk for mastitis determination in cow milk. These values of resistivity

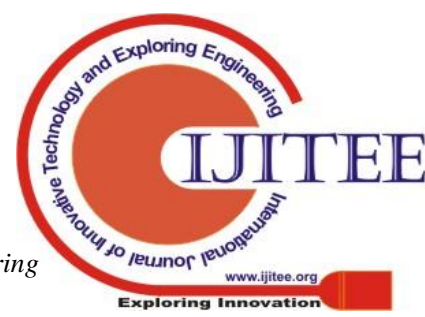


lies in the border range of resistivity values. For this range of resistivity the yellow LED light will glow.

MS3 (milk sample 3) has $2.17 \Omega \mathrm{m}$ value of milk resistivity, and this lies in the acceptable range for mastitis detection. For this value also the green LED will glow for displaying the acceptable range of resistivity of milk for mastitis detection.

MS4 (milk sample 4) has $1.68 \Omega \mathrm{m}$ milk resistivity value, and this value of resistivity of milk lies in the rejected range of resistivity. In this case the red LED light will glow.

\section{CONCLUSION}

Mastitis is the major primeval disease of the dairy cattle and it leads to inflammation of the mammary gland and udder tissue. In mastitis as the udder of the cattle are affected, symptoms of infected udder are swelling, heat, redness, hardness, or pain (pain is also the case of severe mastitis i.e. clinical mastitis). The milk quality, its production, and farm economics are affected negatively by mastitis. Three different regions of Punjab (Bathlana, Mansa, Badmajra) were studied for current status of mastitis on the basis of techniques used to determine the mastitis in the cattle. The proposed setup here provides a low cost solution for detection of mastitis based upon milk samples of cattle. Three ranges of milk resistivity values are considered such as acceptable, moderate and rejected for samples. Acceptable milk range is represented by green LED light, moderate range with a yellow LED, and rejected range is indicated with a red LED light.

\section{REFERENCES}

1. Marcuss Henningnson, Karin Ostergren,and Petr Dejmek, "The electrical conductivity of milk - the effect of dilution and temperature",international journal of food and agriculture,vol $8,15-22,2005$.

2. Ming-Chih Chen, Chein-HsingChen, and Chong-YuSiang, "Design of Information system for Milking Dairy Cattle and Detection of Mastitits", Mathematical Problems in Engineerig, Article ID 759019, 2014.

3. Francesca Gabriele, Thorgeir Lawrence, "Impact of Mastitisin Small Scale Dairy Production Systems", Food and Agriculture Organisation of the United States, 13, 2014.

4. Shagufta Fahmid, Eram Hassan, Hafsa Waeem, Spozhmai Barrech, Shazma Lodhi,and Sidra Latif,"dtermination of mastiti by measuring milk electrical conductivity", international journal of advanced research in biologicla sciences, vol 3(10), 1-4,2016.

5. Mandheer Kaur, Khush Preet Singh, Neha, Yash Hans, Amrit Pal Kaur, Palki Sahib Kaur, Ankit Magotra, "Biotools for Early Diagnosis and Cure of Mastitis, 2016.

6. Jurjen Draaiyer, Brian Dugdill, Anthony Bennett, Jerome Mounsey,"Milk Testing and Payment Systems Resource Book", Food and Agriculture Organisation of United States, 2009.

7. I Panchal, I K sawhney,A K Dang, "Relation between electrical conductivity, dielectric constant, somatic cell count and some other milk quality parameters in diagnosis of subclinical mastitis in Murrah buffaloes", indian journal of dairy science, 69 (3), 2016.

8. Daniella Flavia, Vilas Boas, Anibal Eugenio Vercesi Filho, Mariana Alencar Pereira, Luiz Carios Roma Junior, and Lenira El Faro, "Association between electrical conductivity and milk productio traits in dairy gyr cows",Journal of Applied Animal Research, vol 45, no.1,227-233, 2017.
9. Francisco J. Ferrero, Gustavo Grillo, Perez M A,Juan C. Campo, "Design of a low cost mastitis detector in cows b measuring electrical conductivity of milk", IEEE Instrumentation and Measurement Technology Conferenced, vol 1, 375-378, 2002.

\section{AUTHORS PROFILE}

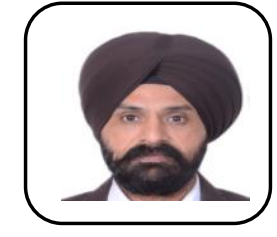

Dr. Harpal Singh is working as Professor in Chandigarh Engineering College, Mohali, India. He has more than 20 years of experience, many national and international journal research papers to his credit and filed three patents. His areas of interest are Image Processing, Control Automation and Watermarking.

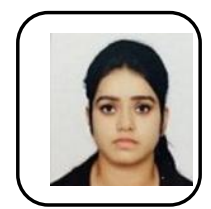

Miss Kanika Chhabra received her degree in B.Tech in ECE from Kurukshetra University in the year 2016. She is currently persuing M.Tech in ECE from Punjab Technical University, Jalandhar. Her research interest are in the field of networking, Image Processing.

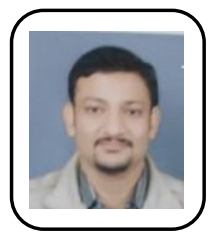

Dr. Rinkesh Mittal is a professor working in CEC in ECE department and having an experience of 15 years. He has published more than 50 research papers in various international journals. His areas of interest are wireless communication, networking. 